\title{
Erratum to: Olive-Mill Wastewater Bacterial Communities Display a Cultivar Specific Profile
}

\author{
George Tsiamis • Georgia Tzagkaraki • \\ Athina Chamalaki • Nikolaos Xypteras · \\ Gary Andersen · Dimitris Vayenas · Kostas Bourtzis
}

Published online: 9 December 2011

(C) Springer Science+Business Media, LLC 2011

\section{Erratum to: Curr Microbiol}

DOI 10.1007/s00284-011-0049-4

The original version of this article unfortunately contained a mistake. The affiliations were incorrect. The present address for Prof. D. Vayenas was unintentionally omitted. His present address is Department of Environmental and Natural Resources Management, University of Western Greece, Agrinio, Greece.

The online version of the original article can be found under doi:10.1007/s00284-011-0049-4.

G. Tsiamis - G. Tzagkaraki - A. Chamalaki · N. Xypteras ·

D. Vayenas $\cdot$ K. Bourtzis $(\bowtie)$

Environmental and Natural Resources Management,

University of Ioannina, Agrinio, Greece

e-mail: kbourtz@uoi.gr

Present Address:

G. Tsiamis · A. Chamalaki - D. Vayenas - K. Bourtzis

Department of Environmental and Natural Resources

Management, University of Western Greece, Agrinio, Greece

G. Andersen

Centre for Environmental Biotechnology, Lawrence Berkeley

National Laboratory, Berkeley, California, USA

D. Vayenas

Foundation for Research and Technology Hellas, Institute of Chemical Engineering and High Temperature Chemical

Processes, Rio, Greece 